\title{
Detailed Componential Characterization of Extractable Species with Organic Solvents from Wheat Straw
}

\author{
Yong-Chao Lu, ${ }^{1}$ Yao Lu, ${ }^{2,3}$ Zhao-Lin Lu, $^{2}$ and Xian-Yong Wei ${ }^{3}$ \\ ${ }^{1}$ School of Basic Education Sciences, Xuzhou Medical University, Xuzhou 221004, China \\ ${ }^{2}$ Advanced Analysis \& Computation Center, China University of Mining \& Technology, Xuzhou 221116, China \\ ${ }^{3}$ Key Laboratory of Coal Processing and Efficient Utilization, Ministry of Education, China University of Mining \& Technology, \\ Xuzhou 221116, China \\ Correspondence should be addressed to Yao Lu; luyimao@163.com
}

Received 17 March 2017; Revised 25 July 2017; Accepted 18 September 2017; Published 1 November 2017

Academic Editor: Nilusha Sudasinghe

Copyright (c) 2017 Yong-Chao Lu et al. This is an open access article distributed under the Creative Commons Attribution License, which permits unrestricted use, distribution, and reproduction in any medium, provided the original work is properly cited.

Componential analysis of extractives is important for better understanding the structure and utilization of biomass. In this investigation, wheat straw (WS) was extracted with petroleum ether (PE) and carbon disulfide $\left(\mathrm{CS}_{2}\right)$ sequentially, to afford extractable fractions $\mathrm{EF}_{\mathrm{PE}}$ and $\mathrm{EF}_{\mathrm{CS} 2}$, respectively. Detailed componential analyses of $\mathrm{EF}_{\mathrm{PE}}$ and $\mathrm{EF}_{\mathrm{CS} 2}$ were carried out with Fourier transform infrared (FTIR) spectroscopy, gas chromatography/mass spectrometry (GC/MS), X-ray photoelectron spectroscopy (XPS), transmission electron microscopy (TEM), energy dispersive spectrometry (EDS), and electron probe microanalysis (EPMA). Total extractives were quantified $4.96 \%$ by weight compared to the initial WS sample. FTIR and GC/MS analyses results showed that $\mathrm{PE}$ was effective for the extraction of ketones and waxes derived compounds; meanwhile $\mathrm{CS}_{2}$ preferred ketones and other species with higher degrees of unsaturation. Steroids were enriched into $\mathrm{EF}_{\mathrm{PE}}$ and $\mathrm{EF}_{\mathrm{CS} 2}$ with considerable high relative contents, namely, $64.52 \%$ and $79.58 \%$, respectively. XPS analysis showed that most of the $\mathrm{C}$ atoms in extractives were contained in the structures of C-C, C-COOR, and C-O. TEM-EDS and EPMA analyses were used to detect trace amount elements, such as $\mathrm{Al}, \mathrm{Si}, \mathrm{P}, \mathrm{S}, \mathrm{Cl}$, and $\mathrm{Ca}$ atoms. Detailed characterization of extractable species from WS can provide more information on elucidation of extractives in biomass.

\section{Introduction}

Biomass has been considered to be a promising feedstock for fuels and chemicals production to substitute fossil resources $[1,2]$. The main components of lignocellulosic biomass are cellulose, hemicellulose, and lignin, accounting for 60-90\% of entire dry weight; other components include extractives, protein, and pectin. Thermochemical or biological techniques $[1,3]$ have been carried out aiming at the conversion of biomass for strategic utilization. Biomass-based fuels, such as bioethanol, biogas, biodiesel, and biooil, have been used as complementary fuels for decades; meanwhile, various value-added chemicals, such as furans, aldehydes, ketones, and aromatics, so-called platform compounds, can also be produced in biorefinery plants [1-3].

Extractives are natural nonstructured nonpolymer components in biomass and are capable of being extracted with water and organic solvents [4]. Chemically, extractives cover a wide range of species, such as aliphatic hydrocarbons, alcohols, acids, fats, terpenes, steroids, resin acids, rosin, phenols, waxes, glycosides, quinines, and proteins, accounting for $5-30 \%$ of dry weight of biomass [4]. The components of the extractives from biomass vary significantly [5] according to the family, genera, and species and even the location, part, age, and season.

Although the extractives are considered to be nonstructural substances with low contents, they play an important role in the attractive forces of adjacent biomass particles [6] by providing weak $\mathrm{H}$-bonding and van der Waal's forces $[7,8]$. Furthermore, extractives may affect subsequent characterization, further degradation processes, and even the utilization of carbohydrates and lignin in biomass. For example, due to incomplete removal in the extraction, residual extractives will precipitate together with insoluble lignin, leading to 
an overestimation of lignin content [9]. In pulping process, serious pitch problem may arise if extractives are not removed effectively; for example, sterols and waxes are insoluble and will deposit in alkaline solutions [5]. In thermochemical conversion of biomass, extractives are decomposed under lower temperature avoiding significant influence on product properties. However, extractives can catalyze the reactions involved in the pyrolysis of biomass [10] and additional products derived from extractives can alter the distribution of the final products [11]. Furthermore, some extractives are potentially toxic to microorganisms which would negatively influence the biochemical conversion of biomass [12]. Therefore, it is necessary to remove them prior to downstream analysis or handling of biomass [13].

The removal of extractives depends heavily on the solvents and conditions used. Generally, water and ethanol extractives contain organic acids, inorganic substances, waxes, nonstructural sugars, and so forth. [14, 15]. Hot water can extract tannins and phenolics effectively from biomass [16-18], while ethanol, acetone, and dichloromethane can remove phytosterols and lipophilic extractives from wood significantly, but leaving fatty acid esters with considerable amounts [11]. Petroleum ether (PE) and carbon disulfide $\left(\mathrm{CS}_{2}\right)$ are organic solvents with low polarities. They can extract alkanes, waxes, benzene-ring containing compounds (BRCCs), fatty acids, and organonitrogen compounds (ONCs) effectively from degraded biomass samples [19-22]. Typical components in extractives can also be enriched in the extraction fractions. PE is effective for the removal of alkanes and waxes in stalks [19] and for the extraction of BRCCs in biooil produced from pyrolysis of rice husk [20]. $\mathrm{CS}_{2}$ was reported to have strong $\pi-\pi$ interaction with fatty acids [21] and ONCs in the extraction [22].

A systematic study showed that wheat straw (WS) was more readily depolymerized with the oxidation of $\mathrm{NaOCl}$ aqueous solution after sequential extraction with several organic solvents [23]. Oxidative degradation of organic components in WS might be hindered by extractives to some extent. In order to explore more information on the extraction process, in this investigation, $\mathrm{PE}$ and $\mathrm{CS}_{2}$ were used as the solvents in the sequential extraction of WS, and detailed characterization of the extraction fractions was carried out. Fourier transform infrared (FTIR) spectroscopy, as a routine technique for analysis of organic substances, was used to determine functional groups in extraction fractions. Difference between WS and extracted WS in their components could be clearly presented. The volatile species in extractives were identified and characterized with gas chromatography/mass spectrometry (GC/MS). GC/MS is a frequently used technique to identify compounds based on the high effective chromatographic separation of species with different volatilities. Mass spectrometer provides high resolution for charged fragments derived from molecules. FTIR and GC/MS are convenient and reliable methods for the analysis of complex samples, such as the degradation products from biomass and coals [24, 25]. The chemical states of elements contained in extractives were assayed by X-ray photoelectron spectroscopy (XPS). Binding types between atoms can be assigned by calculated binding energy.
TABLE 1: Proximate and ultimate analyses (wt.\%) of WS.

\begin{tabular}{llllllll}
\hline \multicolumn{3}{c}{ Proximate analysis } & \multicolumn{5}{c}{ Ultimate analysis } \\
\hline$M_{\mathrm{ad}}$ & $A_{\mathrm{d}}$ & $V_{\mathrm{daf}}$ & $\mathrm{C}$ & $\mathrm{H}$ & $\mathrm{O}^{*}$ & $\mathrm{~N}$ & $\mathrm{~S}$ \\
\hline 8.0 & 8.2 & 70.2 & 42.3 & 6.6 & 50.2 & 0.3 & 0.6 \\
\hline
\end{tabular}

* By difference: $M_{\mathrm{ad}}$, moisture on air dried basis; $A_{\mathrm{d}}$, ash on dry basis; $V_{\mathrm{daf}}$, volatile matter on dry and ash-free basis.

Though it is very expensive to conduct, XPS analysis is useful in understanding the composition of samples by providing fundamental structural information [26, 27]. Transmission electron microscopy (TEM) coupled with energy dispersive spectrometry (EDS) and electron probe microanalysis (EPMA) were employed for the determination of abundance of organic/inorganic atoms in the extraction fractions. TEMEDS method provides accurate qualitative and quantitative analyses for elements with atomic number from $4(\mathrm{Be})$ to 92 (U). The costs of TEM-EDS and EPMA analyses are higher than FTIR and GC/MS analyses since they contain relatively more expensive instruments. They were more often used in elemental analysis of inorganic materials, such as semiconductors and cells. In recent years, EDS was used in the characterization of lignite and its alkali extracted residue [28]. Very few reports were issued on the analysis of inorganic matters derived from biomass $[29,30]$.

\section{Experimental}

2.1. Materials. WS was purchased from Xuzhou, Jiangsu Province, China. It was washed with distilled water for several times to remove sandy soil and then dried in sunlight for more than two months. Then the dried WS was chopped into small pieces and pulverized to pass through an 80mesh sieve $(<180 \mu \mathrm{m})$ followed by desiccation in a vacuum drying oven at $80^{\circ} \mathrm{C}$ for $48 \mathrm{~h}$. Table 1 shows the proximate and ultimate analyses of the dried WS sample. PE and $\mathrm{CS}_{2}$ were of analytical purity and distilled at their boiling points under atmospheric pressure with a Büchi R-134 rotary evaporator to avoid contaminative impurities.

2.2. Extraction. $50.0 \mathrm{~g}$ WS sample and $500 \mathrm{~mL}$ PE were added to a $1 \mathrm{~L}$ beaker, magnetically stirred at $25^{\circ} \mathrm{C}$ for $1 \mathrm{~h}$, and then placed in a thermostatic ultrasonic bath set at $25^{\circ} \mathrm{C}$ for about $6 \mathrm{~h}$. The mixture was filtrated to afford a filter cake $\mathrm{EFC}_{1}$ and a filtrate $\mathrm{EF}_{\mathrm{PE} 1}$. Then the $\mathrm{EFC}_{1}$ was extracted by another $500 \mathrm{~mL}$ of $\mathrm{PE}$ with the same procedure previously used, affording a filter cake $\mathrm{EFC}_{2}$ and a filtrate $\mathrm{EF}_{\mathrm{PE} 2}$. The two filtrates were combined together to afford a solution $\mathrm{EF}_{\mathrm{PE}}$. $\mathrm{EFC}_{2}$ was dried in a vacuum drying oven at $40^{\circ} \mathrm{C}$ for $48 \mathrm{~h}$ to remove the solvent to a constant weight $( \pm 0.01 \mathrm{~g})$. The amount of extractives extracted by PE was calculated as the weight loss based on the initial dried WS.

Then $\mathrm{EFC}_{2}$ was extracted by $\mathrm{CS}_{2}$ with the same procedure used for $\mathrm{PE}$ to afford a solution $\mathrm{EF}_{\mathrm{CS} 2}$ and a filter cake $\mathrm{EFC}_{4}$. The same drying conditions were used for $\mathrm{EFC}_{4}$. The amount of extractives extracted by $\mathrm{CS}_{2}$ was calculated as the weight loss based on the difference between $\mathrm{EFC}_{2}$ and $\mathrm{EFC}_{4} \cdot \mathrm{EF}_{\mathrm{PE}}$ and $\mathrm{EF}_{\mathrm{CS} 2}$ were concentrated to remove the 
solvents drastically by using a Büchi R-134 rotary evaporator while keeping the solvent temperature at $40^{\circ} \mathrm{C}$ under vacuum distillation condition. The dried extractives from $\mathrm{EF}_{\mathrm{PE}}$ and $\mathrm{EF}_{\mathrm{CS} 2}$ were stored in a desiccator at $25^{\circ} \mathrm{C}$.

2.3. FTIR Analysis. The WS sample, extraction residue $\mathrm{EFC}_{4}$, and the extractives from $\mathrm{EF}_{\mathrm{PE}}$ and $\mathrm{EF}_{\mathrm{CS} 2}$ were analyzed with a Nicolet Magna IR-560 FTIR spectrometer using KBr pellet method. The spectra were recorded by collecting 50 scans at a resolution of $8 \mathrm{~cm}^{-1}$ in reflectance mode with a measuring region of $4000-500 \mathrm{~cm}^{-1}$.

2.4. GC/MS Analysis. The extractives were analyzed with a Hewlett-Packard 6890/5973 GC/MS system equipped with a HP-5MS capillary column (cross link 5\% PH ME siloxane, $60 \mathrm{~m} \times 0.25 \mathrm{~mm}$ i.d., $0.25 \mu \mathrm{m}$ film thickness) and a quadrupole analyzer. The compounds were ionized by electron ionization under $70 \mathrm{eV}$. Quadrupole mass analyzer was used to obtain the mass spectra. Helium was used as the carrier gas with a flow rate at $1.0 \mathrm{~mL} / \mathrm{min}$. The column was heated first at a rate of $5^{\circ} \mathrm{C} / \mathrm{min}$ from $60^{\circ} \mathrm{C}$ to $150^{\circ} \mathrm{C}$ and then at a rate of $7^{\circ} \mathrm{C} / \mathrm{min}$ from $150^{\circ} \mathrm{C}$ to $300^{\circ} \mathrm{C}$ (and held at $300^{\circ} \mathrm{C}$ for $40 \mathrm{~min}$ ). Both injector and detector temperatures were set at $300^{\circ} \mathrm{C}$. The scanned mass range was $30-500 \mathrm{~m} / z$. The reproducibility of quantitative analysis for the species was conducted by duplicated injection of the samples. The data were acquired and processed using Chemstation software together with GC/MS system. The species were identified by comparing mass spectra with National Institute of Standards and Technology (NIST) library data according to fragmentation rules of organic species under electron ionization condition.

2.5. XPS Analysis. The XPS analysis was performed on an ESCALAB 250Xi system (Thermo-Fisher, USA). The source gun type was Al K Alpha, and spot size was $900 \mu \mathrm{m}$. Data were recorded by collecting 30 scans in 20 min with pass energy at $20.0 \mathrm{eV}$. Survey scan was conducted within the range $0-1000 \mathrm{eV}$. Peak fitting was used for the spectra to the assignment of different chemical bonds according to specific binding energy.

2.6. TEM-EDS Analysis. $\mathrm{EF}_{\mathrm{PE}}$ sample was dispersed with ethanol, then sprayed with carbon film and loaded on 300mesh copper grids under sonic condition for $10 \mathrm{~min}$, and then dried under lamp. TEM analysis was performed on a Tecnai $\mathrm{G}^{2}$ F20 electron microscope (FEI, USA) at an accelerating voltage of $200 \mathrm{kV}$ and linked to an $\mathrm{X}$-ray analysis system (Oxford EDS 6767). Determination of C atoms was interfered by carbon film introduced in the preparation of the sample. O element was not taken into consideration in the TEM-EDS analysis since previous methods provided detailed results. Inorganic elements with trace amounts in extractives were assayed, such as $\mathrm{Al}, \mathrm{Si}, \mathrm{P}, \mathrm{S}, \mathrm{Cl}$, and $\mathrm{Ca}$ atoms.

2.7. EPMA Analysis. In order to find more information on the elemental composition of $\mathrm{EF}_{\mathrm{PE}}$ and to verify the results obtained with TEM-EDS analysis, EPMA analysis was carried out, especially concentrating on $\mathrm{K}, \mathrm{Na}, \mathrm{Mg}, \mathrm{S}$, and $\mathrm{Ca}$

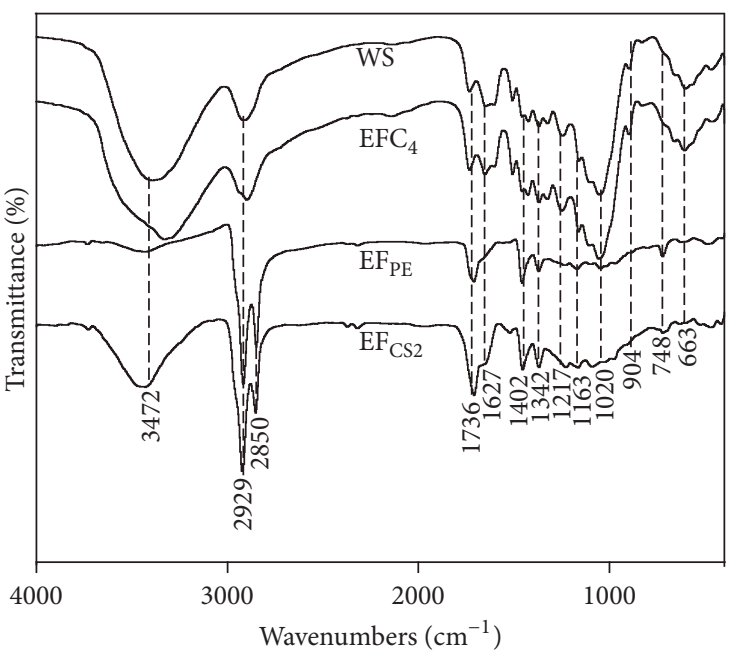

FIGURE 1: FTIR analysis of WS, $\mathrm{EFC}_{4}, \mathrm{EF}_{\mathrm{PE}}$, and $\mathrm{EF}_{\mathrm{CS} 2}$.

elements. The analysis was conducted on an 8050G system (Shimadzu, Japan). Schottky emission mode was used, and the accelerating voltage was $15 \mathrm{kV}$.

\section{Results and Discussions}

3.1. Extraction Yields. The dried $\mathrm{EFC}_{4}$ lost $2.48 \mathrm{~g}$ comparing to the WS sample, indicating that the extractives accounted for $4.96 \%$ of the starting material. $\mathrm{PE}$ and $\mathrm{CS}_{2}$ were removed completely with a rotary evaporator under reduced pressure. The weights of extractives from $\mathrm{EF}_{\mathrm{PE}}$ and $\mathrm{EF}_{\mathrm{CS} 2}$ were $1.66 \mathrm{~g}$ and $0.82 \mathrm{~g}$, respectively. Waxes and BRCCs could be concentrated into $\mathrm{EF}_{\mathrm{PE}}$ because $\mathrm{PE}$ was effective for dewaxing of stalks [19] and for the extracting of BRCCs [20]. Species containing double bond or triple-bond, such as fatty acids, aldehydes, ketones, and ONCs, could be enriched into $\mathrm{EF}_{\mathrm{CS} 2}$ due to their strong $\pi-\pi$ interaction with $\mathrm{CS}_{2}[21,22]$.

3.2. FTIR Analysis. Significant differences were observed in the FTIR spectra of WS sample, $\mathrm{EF}_{\mathrm{PE}}, \mathrm{EF}_{\mathrm{CS} 2}$, and $\mathrm{EFC}_{4}$, as shown in Figure 1. Wide and strong peaks around $3200-3700 \mathrm{~cm}^{-1}$ were attributed to the vibration of $-\mathrm{OH}$; for example, peaks $3450-3650 \mathrm{~cm}^{-1}$ and $3200-3400 \mathrm{~cm}^{-1}$ were assigned to free and associated $-\mathrm{OH}$, respectively. Except for $\mathrm{EFC}_{4}$, all the other three samples showed wide peak around $3500 \mathrm{~cm}^{-1}$, implying the presence of species containing free $\mathrm{OH}$. There was an interesting transformation of absorbance peak before and after the extraction, that is, from free $\mathrm{OH}$ to associated $-\mathrm{OH}$. Species containing free $-\mathrm{OH}$ in extractives can be extracted from WS sample with $\mathrm{PE}$ and $\mathrm{CS}_{2}$, sequentially. Free -OH containing species were enriched in $\mathrm{EF}_{\mathrm{CS} 2}$ rather than $\mathrm{EF}_{\mathrm{PE}}$. Peak around $3300-3500 \mathrm{~cm}^{-1}$ in the spectrum of $\mathrm{EF}_{\mathrm{CS} 2}$ could also be attributed to the vibration of - NH, implying the presence of ONCs [22]. However, in spectrum of $\mathrm{EF}_{\mathrm{PE}}$, only a weak peak was obtained within this range. Peaks around $2929 \mathrm{~cm}^{-1}$ and $2850 \mathrm{~cm}^{-1}$ were attributed to the stretching of $-\mathrm{CH}_{2}-$ and $-\mathrm{CH}_{3}$, implying the presence of alkanes, waxes, aliphatics, and so forth. Fine 

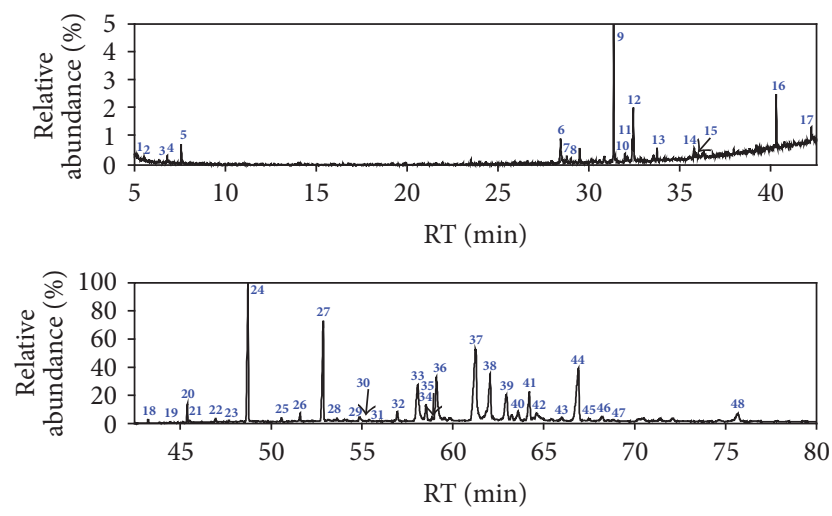

Figure 2: TICs of $\mathrm{EF}_{\mathrm{PE}}$ from WS.

structures of spectra were only observed for the two extracts, namely, $\mathrm{EF}_{\mathrm{PE}}$ and $\mathrm{EF}_{\mathrm{CS} 2}$, implying the selectivity of these two solvents for $-\mathrm{CH}_{2}$ - and $-\mathrm{CH}_{3}$ containing species. The intense peaks around $1736 \mathrm{~cm}^{-1}$ and $1627 \mathrm{~cm}^{-1}$ were attributed to the vibration of $\mathrm{C}=\mathrm{O}$, indicating the presence of aldehydes, ketones, carboxylic acids, esters, and so forth [31]. All the four samples contained the peak at $1736 \mathrm{~cm}^{-1}$ with similar intensity. However, the peaks at $1627 \mathrm{~cm}^{-1}$ were weaker in spectra of $\mathrm{EF}_{\mathrm{PE}}$ and $\mathrm{EF}_{\mathrm{CS} 2}$. Peak around $1402 \mathrm{~cm}^{-1}$ could be assigned to the bending of $\mathrm{C}-\mathrm{H}$ in aliphatics, $\mathrm{O}-\mathrm{H}$ in carboxylic acids, $\mathrm{C}-\mathrm{O}-\mathrm{H}$ in alcohols, and so forth. This peak was common in each spectrum of samples. Peaks around $1736 \mathrm{~cm}^{-1}, 1627 \mathrm{~cm}^{-1}$, and $1402 \mathrm{~cm}^{-1}$ could also be assigned to characteristic absorption of ONCs, namely, amide I and II bands and $-\mathrm{NO}_{2}$ stretching, respectively [22]. Peaks at $1163 \mathrm{~cm}^{-1}, 1020 \mathrm{~cm}^{-1}$, and $663 \mathrm{~cm}^{-1}$ were assigned to stretching of C-O-C and in-plane bending of aromatic $\mathrm{C}-\mathrm{H}$, which were observed obviously in the spectra of WS and $\mathrm{EFC}_{4}$. The C-O-C structure can be found in almost all kinds of hemicelluloses and cellulose in biomass and the aromatic C$\mathrm{H}$ present in lignins. In the spectra of $\mathrm{EF}_{\mathrm{PE}}$ and $\mathrm{EF}_{\mathrm{CS} 2}$, peaks around $748 \mathrm{~cm}^{-1}$ were attributed to the stretching of $-\mathrm{CH}_{2}-$ in waxes and aliphatics [32]. The difference between WS and $\mathrm{EFC}_{4}$ spectra was difficult to figure out; meanwhile $\mathrm{EF}_{\mathrm{PE}}$ and $\mathrm{EF}_{\mathrm{CS} 2}$ shared very similar spectrum. Significant differences between the two groups (WS/ $\mathrm{EFC}_{4}$ and $\mathrm{EF}_{\mathrm{PE}} / \mathrm{EF}_{\mathrm{CS} 2}$ ) lie in peaks around $3200-3700 \mathrm{~cm}^{-1}$ and $1020 \mathrm{~cm}^{-1}$, indicating different states of $-\mathrm{OH}$ and presence of aromatic $\mathrm{C}-\mathrm{H}$.

3.3. GC/MS Analysis of the Species in the Extracts. In total, 48 and 27 compounds were identified in $\mathrm{EF}_{\mathrm{PE}}$ and $\mathrm{EF}_{\mathrm{CS} 2}$, respectively, with GC/MS analysis. The total ionic chromatograms (TICs) were presented in Figures 2 and 3, respectively. These species can be classified into alkanes, alkenes, arenes, alcohols, furan, aldehydes, ketones, ONCs, carboxylic acid (CA), esters, and others, as listed in Tables S1 and S2 (see Supplementary Material available online at https://doi.org/10.1155/2017/7305682). Double bond equivalent $(\mathrm{DBE})$ was calculated for each species identified in $\mathrm{EF}_{\mathrm{PE}}$ and $\mathrm{EF}_{\mathrm{CS} 2}$; and the plot of $\mathrm{DBE}$ versus carbon number was used to demonstrate the degrees of unsaturation of compounds, shown in Figure 4. From the plot, one can
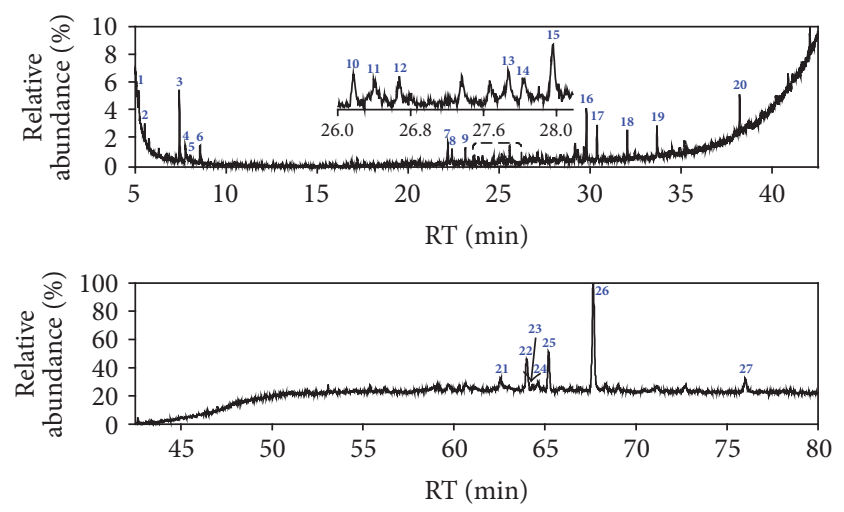

FIgure 3: TICs of $\mathrm{EF}_{\mathrm{CS} 2}$ from WS.

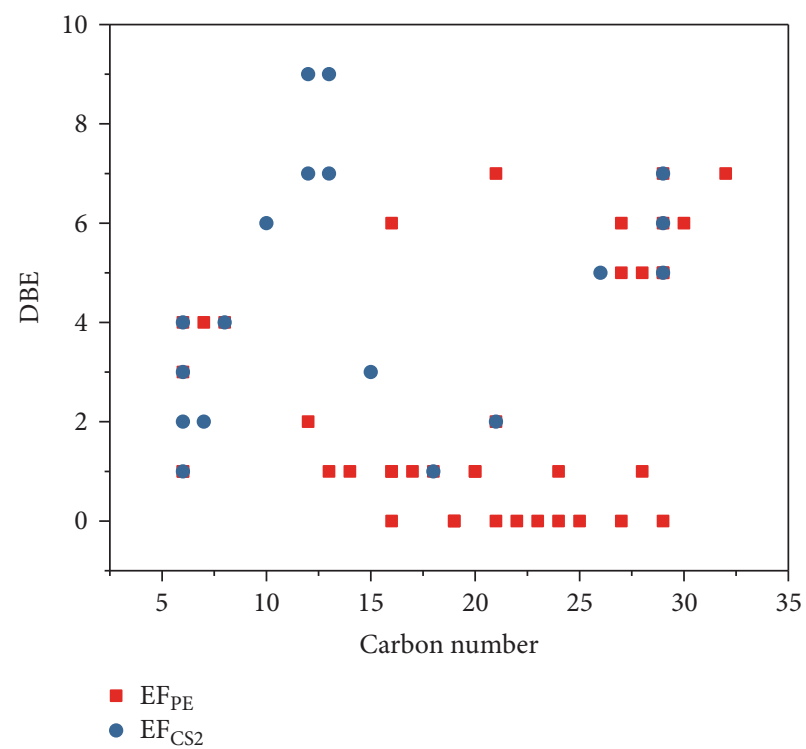

FIGURE 4: The relationship between DBE and carbon number for compounds identified in $\mathrm{EF}_{\mathrm{PE}}$ and $\mathrm{EF}_{\mathrm{CS} 2}$.

observe that compounds were roughly divided into two groups in these two samples, namely, lower DBE group and higher DBE group. $\mathrm{CS}_{2}$ favors species with higher DBEs and less carbon numbers, while species with more carbon numbers and lower DBEs were enriched in PE.

Various long-chain alkanes, alkenes, and aldehydes derived from waxes were identified, which could be extracted easily by $\mathrm{PE}$ [19]. Two arenes were identified in $\mathrm{EF}_{\mathrm{PE}}$ ( 1 and $3)$. Eight alkanes with carbon numbers ranging from 16 to 29 were detected. All the 5 alcohols identified were sterols. Only one furan was identified, that is, 2,5-dimethylfuran (2), which could be derived from cellulose and hemicelluloses [33]. For the contents of the classes of compounds identified in $\mathrm{EF}_{\mathrm{PE}}$, ketones, alkanes, alcohols, and ONCs were abundant, as shown in Figure 5. Ketones were the most abundant species in $\mathrm{EF}_{\mathrm{PE}}$. Besides alkanones (11 and 12) and furanone (16), abundance sterones were identified $(35,39-42,44-46$, and 48). Sterols and sterones are typical species in extractives with considerable amounts, which can be extracted easily with 


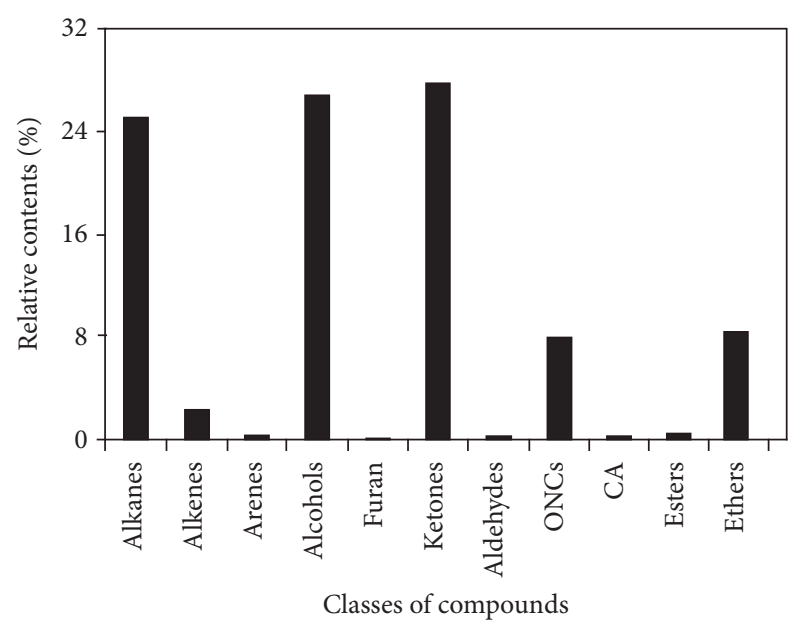

FIGURE 5: Relative contents of classes of compounds identified in $\mathrm{EF}_{\mathrm{PE}}$.

solvents. Extractives were considered as potential material for production of medicine for pharmaceutical utilization based on the steroids components, such as sterols and sterones [34]. Sterones tablets containing testosterone, norethindrone, methandienone, and so forth have been used for treatment of many diseases. There were 17 steroids identified in the $\mathrm{EF}_{\mathrm{PE}}$, accounting for about $64.52 \%$ in relative content, such as cholests and stigmasts. Among them, the most abundant were 22,23-dihydrostigmasterol (37) and stigmastane-3,6dione (44). N,4-Dimethylbenzenesulfonamide (6) was the only one sulfur-containing species identified. Two of the esters identified, namely, butyl methyl phthalate (10) and dipropyl phthalate (13), might be impurities coming from the GC/MS system with plastic or rubber devices or contaminants introduced in the process of sample preparation [35].

Compounds identified in $\mathrm{EF}_{\mathrm{CS} 2}$ with $\mathrm{GC} / \mathrm{MS}$ analysis can be classified into arenes, alcohols, furans, ONC, ketones, and esters, as listed in Table S2. Neither alkanes nor alkenes were identified in the $\mathrm{EF}_{\mathrm{CS} 2}$, and no species that could be derived from waxes were found. Besides benzene (1) and xylene (5), acenaphthene (9) and 9H-fluorene (14) were identified and grouped into the arenes. All the three alcohols identified were steroids (15, 21, and 23). 2,5-Dimethylfuran (2) and dibenzofuran (11) may be derived from the hemicellulose and lignin, respectively. Similar with $\mathrm{EF}_{\mathrm{PE}}$, ketones were the most abundant class identified in $\mathrm{EF}_{\mathrm{CS} 2}$ and could be classified further into alkanones ( 3 and 16), cycloalkanone (6), furanone (20), alkenone (8), and sterones (24-27). Seven steroids were identified in the $\mathrm{EF}_{\mathrm{CS} 2}$ with relative content of $79.58 \%$. The four phthalates identified $(7,13,17$, and 18$)$ might not be the components in the extractives, which could be considered as impurities or contaminants [35]. The relative contents of the classes of compounds identified in $\mathrm{EF}_{\mathrm{CS} 2}$ were shown in Figure 6. Ketones, esters, and alcohols were the three most abundant classes.

3.4. XPS Analysis. As displayed in Figure 7, $101.8 \mathrm{eV}, 284.1 \mathrm{eV}$, and $531.9 \mathrm{eV}$ were attributed to $\mathrm{Si} 2 p, \mathrm{C} 1 s$, and $\mathrm{O} 1 s$ [36],
TABLE 2: Chemical statuses of $\mathrm{C}$ and $\mathrm{Si}$ atoms in $\mathrm{EF}_{\mathrm{PE}}$ analyzed with XPS.

\begin{tabular}{lcccc}
\hline Chemical bond & BE $(\mathrm{eV})$ & FWHM $(\mathrm{eV})$ & Area & Atomic $(\%)$ \\
\hline C-C & 284.9 & 1.01 & 34722.3 & 48.54 \\
C-COOR & 285.3 & 0.98 & 18089.1 & 25.29 \\
C-O & 286.4 & 1.42 & 8333.9 & 11.66 \\
-C=O & 287.9 & 1.13 & 1899.8 & 2.66 \\
O-C=O & 289.1 & 1.01 & 1779.9 & 2.49 \\
Si-O & 102.1 & & 166.8 & 0.38 \\
& 102.7 & 0.91 & 85.1 & 0.01 \\
\hline
\end{tabular}

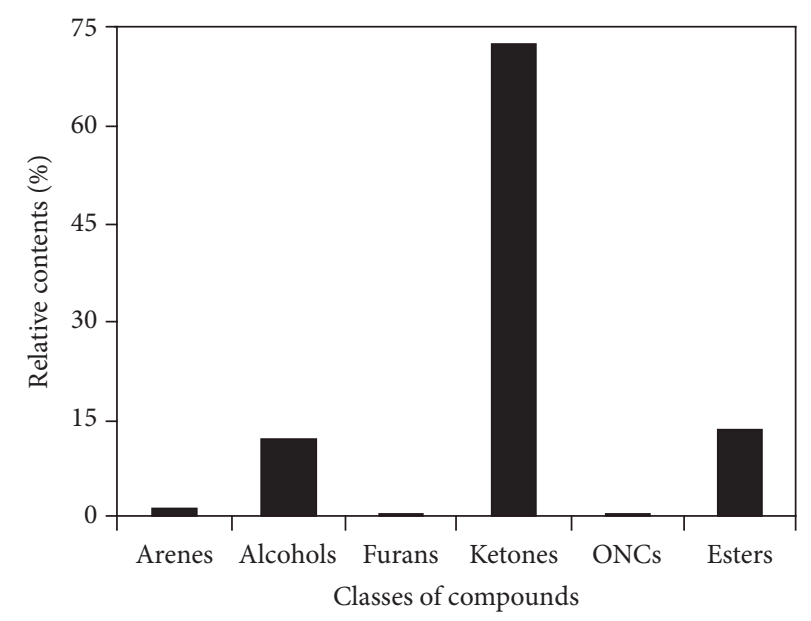

FIGURE 6: Relative contents of classes of compounds identified in $\mathrm{EF}_{\mathrm{CS} 2}$.

respectively, implying the presence of the $\mathrm{Si}-, \mathrm{C}-$, and $\mathrm{O}-$ containing species in $\mathrm{EF}_{\mathrm{PE}}$. Peak fittings for $\mathrm{C} 1 \mathrm{~s}$ and $\mathrm{Si}$ $2 p$ were conducted (see (b) and (c) in Figure 7) and the resulting peaks were assigned for different chemical bonds indicating the status of $\mathrm{C}, \mathrm{O}$, and $\mathrm{Si}$ atoms according to their special binding energy (BE), as shown in Table 2. The full width at half maximum (FWHM) of each chemical bond was also calculated. According to the atomic percentage for specific chemical bond, $\mathrm{C}$ atoms contained in $\mathrm{C}-\mathrm{C}$ bond accounted for $48.54 \%$ indicating the presence of high amount of long-chain aliphatic species, such as alkanes, waxes, and/or steroids, which is consistent with the componential analysis by GC/MS. C-COOR containing species could be attributed to fatty acids and esters holding $25.29 \%$ of $\mathrm{C}$ atoms. Other types of $\mathrm{C}$ atoms were in $\mathrm{C}-\mathrm{O}, \mathrm{C}=\mathrm{O}$, and $\mathrm{O}-\mathrm{C}=\mathrm{O}$ structures [36]. Si-O bond was divided into two bonds in peak fitting, namely, $102.1 \mathrm{eV}$ and $102.7 \mathrm{eV}$, which could be assigned to $\mathrm{Si}_{2} \mathrm{O}_{3}$ and $\mathrm{SiO}_{2}$, respectively. XPS is a surface-sensitive technique by providing accurate qualitative and quantitative analyses of elemental composition, chemical state, and electronic state of the elements in a sample. It can be used as complementary method along with FTIR and GC/MS analyses to characterize complex samples derived from biomass. 


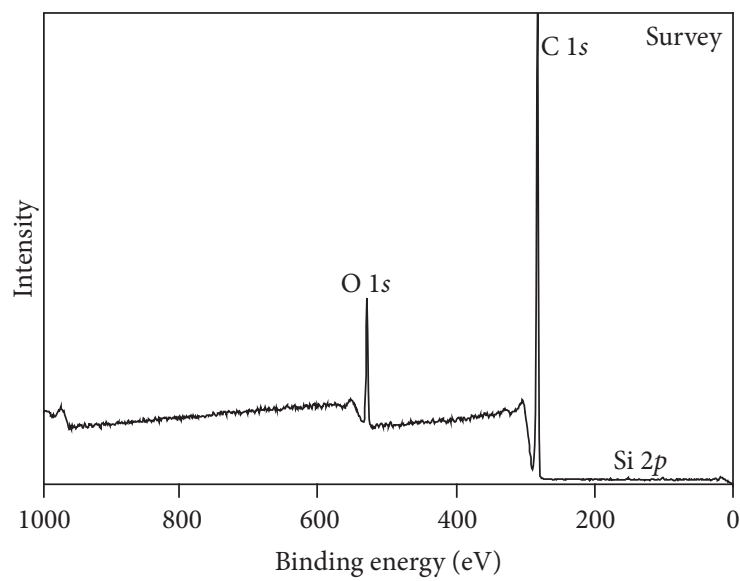

(a)

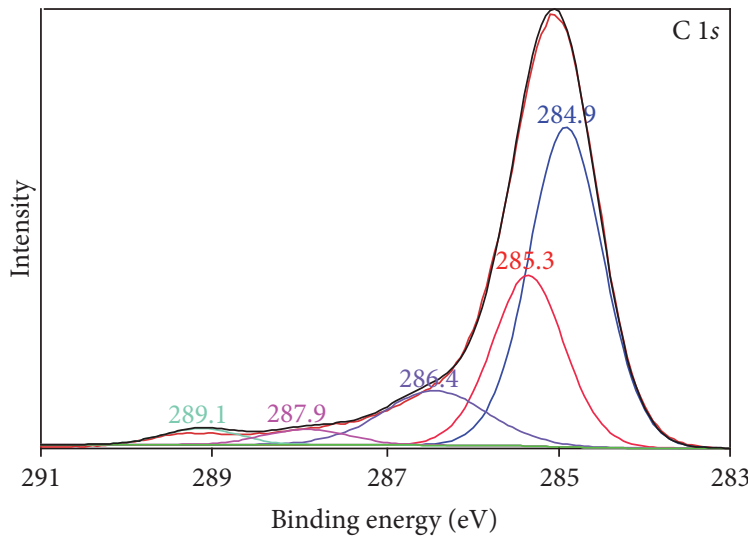

(b)

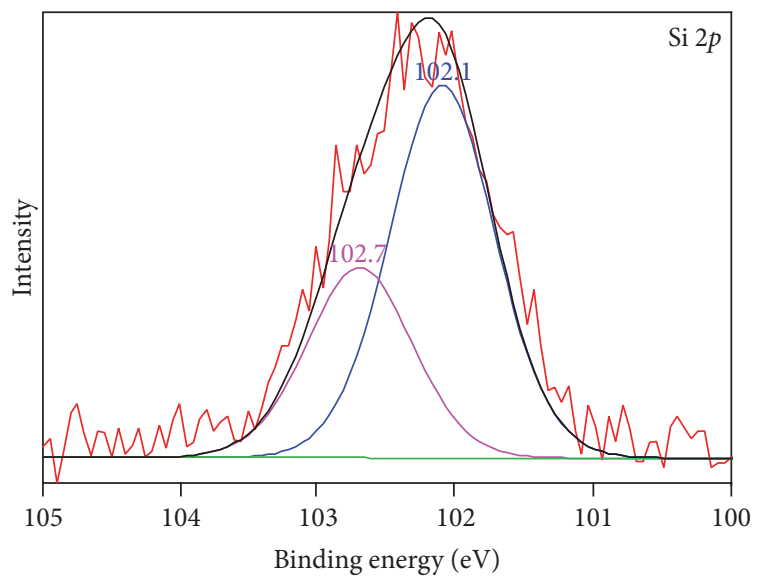

(c)

FIGURE 7: XPS analysis of $\mathrm{EF}_{\mathrm{PE}}$. ((a) survey scan of the sample; (b) peak fitting of the C $1 s$; and (c) peak fitting of the Si $2 p$.)

3.5. TEM-EDS Analysis. As shown in Figure S1 (Supporting Information), two areas (Areas 1 and 2) were selected for the scanning and determining elements with TEM-EDS in $\mathrm{EF}_{\mathrm{PE}}$. Data were collected from six points in each area. Carbon film was used in the sample preparation, and it would interfere with the identification of $\mathrm{C}$ atoms. $\mathrm{C}$ and $\mathrm{O}$ elements were not considered in the detection with TEM-EDS analysis.
TABLE 3: TEM-EDS analysis of elements and their percentages of weight (wt.\%) in $\mathrm{EF}_{\mathrm{PE}}$.

\begin{tabular}{cccccccc}
\hline Areas & Data points & $\mathrm{Al}(\mathrm{K})$ & $\mathrm{Si}(\mathrm{K})$ & $\mathrm{P}(\mathrm{K})$ & $\mathrm{S}(\mathrm{K})$ & $\mathrm{Cl}(\mathrm{K})$ & $\mathrm{Ca}(\mathrm{K})$ \\
\hline & 1 & 32.64 & $\mathrm{Nd}$ & 28.54 & 30.67 & 8.12 & $\mathrm{Nd}$ \\
1 & 2 & 3.11 & 4.78 & $\mathrm{Nd}$ & $\mathrm{Nd}$ & $\mathrm{Nd}$ & 92.09 \\
& 3 & 3.60 & 16.91 & $\mathrm{Nd}$ & 0.36 & $\mathrm{Nd}$ & 79.11 \\
& 4 & 10.72 & 15.50 & $\mathrm{Nd}$ & $\mathrm{Nd}$ & $\mathrm{Nd}$ & 73.77 \\
& 5 & $\mathrm{Nd}$ & 75.96 & 10.70 & $\mathrm{Nd}$ & 13.32 & $\mathrm{Nd}$ \\
& 6 & $\mathrm{Nd}$ & 61.01 & 6.53 & 11.06 & 21.39 & $\mathrm{Nd}$ \\
& Average & 8.35 & 29.03 & 7.63 & 7.02 & 7.14 & 40.83 \\
\hline \multirow{4}{*}{2} & 1 & 3.65 & 16.96 & $\mathrm{Nd}$ & 38.71 & 5.43 & 35.22 \\
& 2 & $\mathrm{Nd}$ & 4.85 & 0.33 & 46.20 & $\mathrm{Nd}$ & 48.60 \\
& 3 & $\mathrm{Nd}$ & 47.59 & 49.64 & $\mathrm{Nd}$ & $\mathrm{Nd}$ & 2.76 \\
& 4 & $\mathrm{Nd}$ & 49.74 & 9.59 & 19.68 & 9.20 & 11.76 \\
& 5 & 13.09 & $\mathrm{Nd}$ & $\mathrm{Nd}$ & 37.81 & $\mathrm{Nd}$ & 49.08 \\
& 6 & $\mathrm{Nd}$ & 61.88 & 21.15 & 16.96 & $\mathrm{Nd}$ & $\mathrm{Nd}$ \\
& Average & 2.79 & 30.17 & 13.45 & 26.56 & 2.44 & 24.57 \\
\hline
\end{tabular}

Nd: not detected.

$\mathrm{Al}, \mathrm{Si}, \mathrm{P}, \mathrm{S}, \mathrm{Cl}$, and $\mathrm{Ca}$ atoms were counted on the data point of $\mathrm{EF}_{\mathrm{PE}}$ and the results were listed in Table 3. Ca, $\mathrm{Si}$, and $\mathrm{S}$ atoms were counted with higher intensities for both areas, which may present in inorganic materials or complexes. Si is known as beneficial element for wheat straw $[37,38]$. Morphological silica materials, such as $\mathrm{SiO}_{2}$, can be obtained by thermochemical treatments [39]. Phytoliths are the main forms of Si uptaken by wheat straw [40]. Then the Si-containing species deposit within different intracellular and extracellular structures. Ca atoms were detected in the extractives with comparable accounts to $\mathrm{Si}$. Calcium oxalate is another main component in phytoliths [41, 42] together with Si-containing species. The concentration of Si in WS ranges from 1.5 to $12 \mathrm{~g} / \mathrm{kg}$ [43], while Ca content in WS is around $5.6 \mathrm{~g} / \mathrm{kg}$ [44]. Current application of the $\mathrm{Ca}$ and $\mathrm{Si}$ in biomass was concentrated on the production of ash and further for the preparation of value-added materials, such as catalyst [45]. By using organic solvents in the extraction, namely, $\mathrm{PE}$ and $\mathrm{CS}_{2}$, only trace amounts of $\mathrm{Si}$ and $\mathrm{Ca}$ were extracted since most of them were in their inorganic forms. $\mathrm{S}$ atoms were also counted with similar amounts to $\mathrm{Si}$ and $\mathrm{Ca}$ atoms near Area 2. The content of S in WS was in the range of $0.1-0.7 \%$ (air dried basis) $[46,47]$. Sulfur atom is building block of some proteins and a key ingredient in the formation of chlorophyll. Most of the sulfur is assimilated by the roots in the form of $\mathrm{SO}_{4}{ }^{2-}$. Then it is stored in the form of sulfate and metabolized and/or incorporated into organic structures. It was reported that almost all the sulfur in rice hull occurs in organic form [48]. However, only one sulfur-containing compound was detected in GC/MS analysis of extracts ( $N$,4-dimethylbenzenesulfonamide in $\mathrm{EF}_{\mathrm{PE}}$, see Table S1 in Supporting Information). In biomass, most of Al, $\mathrm{P}$, and $\mathrm{Cl}$ atoms are in their inorganic forms. Among them, the existence of $\mathrm{P}$ atoms could be attributed to phosphate in biomass. Phosphate fertilizer is important for the growth of plants and will be stored mainly in the form of phosphate. 
In order to obtain more accurate information of inorganic substances, more data points should be collected; however, due to the intrinsic limitation of TEM-EDS analysis, only qualitative and semiquantitative results can be obtained. The detection of inorganic substances with trace amounts relies on the progress of in situ analytical techniques with higher resolutions. Meanwhile, enlarging the number of data points is necessary to achieve more accurate and representative analytical results.

3.6. EPMA Analysis. Similar qualitative results for trace amount of elements were obtained by EPMA. Eight data points were selected for $\mathrm{EF}_{\mathrm{PE}}$. Sample image and net intensities for $\mathrm{C}, \mathrm{Na}, \mathrm{Mg}, \mathrm{Si}, \mathrm{S}, \mathrm{K}$, and $\mathrm{Ca}$ atoms of each data point were presented in Figure S2 (Supporting Information). In EPMA, metal elements $\mathrm{K}, \mathrm{Na}$, and $\mathrm{Mg}$ were identified well in the $\mathrm{EF}_{\mathrm{PE}}$. Metal ions are usually in the forms of oxides presented in ash after the combustion of biomass [49]. K and $\mathrm{Na}$ atoms, in their forms of cations, are crucially important nutrients affecting most of the biochemical and physiological processes to promote plant growth and metabolism [50, 51]. $\mathrm{Mg}$ is one of the most important nutrients to plants. It provides the central ions of chlorophyll to accomplish photosynthesis in plants and is involved in many enzyme activities and the structural stabilization of tissues [52]. Due to intrinsic restriction, similar with TEM-EDS analysis, EPMA provides qualitative and semiquantitative results of inorganic elements.

\section{Conclusions}

The $\mathrm{PE}$ and $\mathrm{CS}_{2}$ extractable extractives were weighted up to $4.96 \%$ of initial WS material. Detailed componential characterization of the extractives was carried out by FTIR, GC/MS, TEM-EDS, EPMA, and XPS. FTIR and GC/MS analyses can be treated as universal techniques used in the compositional characterization of complex samples containing various organic species. $\mathrm{PE}$ and $\mathrm{CS}_{2}$ were proved to be effective solvents for extraction of waxes, ketones, esters, and ONCs. Among the detected compounds with GC/MS, ketones were the most abundant species in the two extraction fractions. Other classes of species were alkanes, alkenes, alcohols, aldehydes, ONCs, and so forth. Considerable amounts of steroids especially sterones were identified. This kind of species could be used for medicine production. Trace amounts of atoms including $\mathrm{Ca}, \mathrm{Si}, \mathrm{K}, \mathrm{Cl}, \mathrm{Na}$, and $\mathrm{S}$ were counted with EDS in extractives. EPMA provided similar results with TEM-EDS analysis. Chemical bonds and their abundances were assigned for $\mathrm{C}, \mathrm{O}$, and $\mathrm{Si}$ by using XPS analysis. Most of the $\mathrm{C}$ atoms in the species of extractives were contained in the structures of $\mathrm{C}-\mathrm{C}, \mathrm{C}-\mathrm{COOR}$, and $\mathrm{C}$ $\mathrm{O}$. $\mathrm{Si}$ atoms could be assigned in $\mathrm{Si}-\mathrm{O}$ structures contained in $\mathrm{Si}_{2} \mathrm{O}_{3}$ and $\mathrm{SiO}_{2}$.

FTIR analysis can be used to determine the functional group changes in the sample before and after extraction, and GC/MS analysis is suitable for the detection of volatile organic species providing more accurate information of individuals. These two techniques were used conventionally and effectively in the compositional analysis of complex samples. TEM-EDS and EPMA analyses are nondestructive techniques providing detailed information on the composition of elements and the contents of various atoms, especially for inorganic elements rather than $\mathrm{C}$ atoms. By calculating the BEs of atoms in specific chemical bonds, XPS analysis can provide fundamental structural information that is useful for understanding the composition of complex samples. Generally, the later three analytical methods are more expensive than the former two. Based on the intrinsic properties of the samples in this investigation, FTIR, GC/MS, and XPS were recommended methods used in industries. Comprehensive understanding of the composition of extractives and other complex samples relies on the combination of the advanced analytical techniques.

\section{Conflicts of Interest}

The authors declare that they have no conflicts of interest.

\section{Acknowledgments}

This work was supported by the Fundamental Research Funds for the Central Universities (Grant 2014QNA83), the National Natural Science Foundation of China (Grant no. 21506250), and the Natural Science Foundation of Jiangsu Province (Grant no. BK20150182).

\section{References}

[1] H. M. Morgan, Q. Bu, J. Liang et al., "A review of catalytic microwave pyrolysis of lignocellulosic biomass for value-added fuel and chemicals," Bioresource Technology, vol. 230, pp. 112121, 2017.

[2] T. Kan, V. Strezov, and T. J. Evans, "Lignocellulosic biomass pyrolysis: a review of product properties and effects of pyrolysis parameters," Renewable \& Sustainable Energy Reviews, vol. 57, pp. 1126-1140, 2016.

[3] S. S. Ail and S. Dasappa, "Biomass to liquid transportation fuel via Fischer Tropsch synthesis - Technology review and current scenario," Renewable \& Sustainable Energy Reviews, vol. 58, pp. 267-286, 2016

[4] J. B. Sluiter, R. O. Ruiz, C. J. Scarlata, A. D. Sluiter, and D. W. Templeton, "Compositional analysis of lignocellulosic feedstocks. 1. Review and description of methods," Journal of Agricultural and Food Chemistry, vol. 58, no. 16, pp. 9043-9053, 2010.

[5] S. H. Ghaffar and M. Fan, "An aggregated understanding of physicochemical properties and surface functionalities of wheat straw node and internode," Industrial Crops and Products, vol. 95, pp. 207-215, 2017.

[6] N. P. K. Nielsen, D. J. Gardner, and C. Felby, "Effect of extractives and storage on the pelletizing process of sawdust," Fuel, vol. 89, no. 1, pp. 94-98, 2010.

[7] W. Stelte, J. K. Holm, A. R. Sanadi, S. Barsberg, J. Ahrenfeldt, and U. B. Henriksen, "A study of bonding and failure mechanisms in fuel pellets from different biomass resources," Biomass \& Bioenergy, vol. 35, no. 2, pp. 910-918, 2011.

[8] Z. Liu, A. Quek, and R. Balasubramanian, "Preparation and characterization of fuel pellets from woody biomass, agroresidues and their corresponding hydrochars," Applied Energy, vol. 113, pp. 1315-1322, 2014. 
[9] S. Burkhardt, L. Kumar, R. Chandra, and J. Saddler, "How effective are traditional methods of compositional analysis in providing an accurate material balance for a range of softwood derived residues?" Biotechnology for Biofuels, vol. 6, no. 1, pp. 90-99, 2013.

[10] E. Ranzi, M. Corbetta, F. Manenti, and S. Pierucci, "Kinetic modeling of the thermal degradation and combustion of biomass," Chemical Engineering Science, vol. 110, pp. 2-12, 2014.

[11] E. Mészáros, E. Jakab, and G. Várhegyi, “TG/MS, Py-GC/MS and THM-GC/MS study of the composition and thermal behavior of extractive components of Robinia pseudoacacia," Journal of Analytical and Applied Pyrolysis, vol. 79, no. 1-2, pp. 61-70, 2007.

[12] W. Peng, Q. Xue, and M. Ohkoshi, "Immune effects of extractives on bamboo biomass self-plasticization," Pakistan Journal of Pharmaceutical Sciences, vol. 27, no. 4, pp. 991-999, 2014.

[13] A. Sluiter, R. Ruiz, C. Scarlata, J. Sluiter, and D. Templeton, Determination of Extractives in Biomass, National Renewable Energy Laboratory, Golden, CO., http://www.nrel.gov/biomass/ pdfs/42619.pdf/.

[14] S.-F. Chen, R. A. Mowery, C. J. Scarlata, and C. K. Chambliss, "Compositional analysis of water-soluble materials in corn stover," Journal of Agricultural and Food Chemistry, vol. 55, no. 15, pp. 5912-5918, 2007.

[15] A. Garcia-Maraver, D. Salvachúa, M. J. Martínez, L. F. Diaz, and M. Zamorano, "Analysis of the relation between the cellulose, hemicellulose and lignin content and the thermal behavior of residual biomass from olive trees," Waste Management, vol. 33, no. 11, pp. 2245-2249, 2013.

[16] R. C. Sun and J. Tomkinson, "Comparative study of organic solvent-soluble and water-soluble lipophilic extractives from wheat straw 2: Spectroscopic and thermal analysis," Journal of Wood Science, vol. 48, no. 3, pp. 222-226, 2002.

[17] R. C. Sun and J. Tomkinson, "Comparative study of organic solvent and water-soluble lipophilic extractives from wheat straw I: Yield and chemical composition," Journal of Wood Science, vol. 49, no. 1, pp. 47-52, 2003.

[18] R. C. Sun, D. Salisbury, and J. Tomkinson, "Chemical composition of lipophilic extractives released during the hot water treatment of wheat straw," Bioresource Technology, vol. 88, no. 2, pp. 95-101, 2003.

[19] W. Zhao, Z. Zong M, J. Lin et al., "Dewaxing from stalks with petroleum ether by different methods," Energy \& Fuels, vol. 21, no. 2, pp. 1165-1168, 2007.

[20] Y. Lu, X.-Y. Wei, J.-P. Cao et al., "Characterization of a bio-oil from pyrolysis of rice husk by detailed compositional analysis and structural investigation of lignin," Bioresource Technology, vol. 116, pp. 114-119, 2012.

[21] M.-J. Ding, Z.-M. Zong, Y. Zong et al., "Isolation and identification of fatty acid amides from Shengli coal," Energy \& Fuels, vol. 22, no. 4, pp. 2419-2421, 2008.

[22] Y. Lu, X.-Y. Wei, Z.-M. Zong et al., “Organonitrogen compounds identified in degraded wheat straw by oxidation in a sodium hypochlorite aqueous solution," Fuel, vol. 109, pp. 61-67, 2013.

[23] Y. Lu, Sequential oxidation of rice husk, wheat straw and their extraction residues [Ph. D. Thesis], China University of Mining \& Technology, 2013.

[24] L. Feng, G. Zhao, Y. Zhao, M. Zhao, and J. Tang, "Construction of the molecular structure model of the Shengli lignite using TG-GC/MS and FTIR spectrometry data," Fuel, vol. 203, pp. 924-931, 2017.
[25] F. Wei, J. Cao P, X. Zhao Y et al., "Nitrogen evolution during fast pyrolysis of sewage sludge under inert and reductive atmospheres," Energy \& Fuels, vol. 31, no. 7, pp. 7191-7196, 2017.

[26] G. Jiang, G. A. Husseini, L. L. Baxter, and M. R. Linford, "Analysis of straw by X-ray Photoelectron Spectroscopy," Surface Science Spectra, vol. 11, no. 2, pp. 91-96, 2004.

[27] D.-Y. Xu, J. Jin, Y. Yan et al., "Characterization of biochar by $\mathrm{X}$-ray photoelectron spectroscopy and $13 \mathrm{C}$ nuclear magnetic resonance," Guang Pu Xue Yu Guang Pu Fen Xi/Spectroscopy and Spectral Analysis, vol. 34, no. 12, pp. 3415-3418, 2014.

[28] C. Wang F, X. Fan, F. Zhang et al., "Characterization of humic acids extracted from a lignite and interpretation for the mass spectra," RSC Advances, vol. 7, pp. 20677-20684, 2017.

[29] M. Gopi Kiran, K. Pakshirajan, and G. Das, "Heavy metal removal using sulfate-reducing biomass obtained from a labscale upflow anaerobic-packed bed reactor," Journal of Environmental Engineering, vol. 142, no. 9, article C4015010, 2016.

[30] L. Xu, X. Zheng, H. Cui, Z. Zhu, J. Liang, and J. Zhou, "Equilibrium, kinetic, and thermodynamic studies on the adsorption of cadmium from aqueous solution by modified biomass ash," Bioinorganic Chemistry and Applications, vol. 2017, Article ID 3695604, 9 pages, 2017.

[31] Z. Hao, J. Cao, Y. Wu et al., "Preparation of porous carbon sphere from waste sugar solution for electric double-layer capacitor," Journal of Power Sources, vol. 361, pp. 249-258, 2017.

[32] T. Attard M, C. McElroy R, and J. Hunt A, "Economic assessment of supercritical CO2 extraction of waxes as part of a maize stover biorefinery," International Journal of Molecular Sciences, vol. 16, pp. 17546-17564, 2015.

[33] I. Delidovich, K. Leonhard, and R. Palkovits, "Cellulose and hemicellulose valorisation: An integrated challenge of catalysis and reaction engineering," Energy \& Environmental Science, vol. 7, no. 9, pp. 2803-2830, 2014.

[34] E. William N, K. Alan D, and Steroids., "Pharmacology, complications, and practice delivery issue," The Ochsner Journal, vol. 14, no. 2, article 4052587, 2014.

[35] B. O. Keller, J. Sui, A. B. Young, and R. M. Whittal, "Interferences and contaminants encountered in modern mass spectrometry," Analytica Chimica Acta, vol. 627, no. 1, pp. 71-81, 2008.

[36] H. Bubert, J. Lambert, and P. Burba, "Structural and elemental investigations of isolated aquatic humic substances using Xray photoelectron spectroscopy," Fresenius' Journal of Analytical Chemistry, vol. 368, no. 2-3, pp. 274-280, 2000.

[37] C. Atik and S. Ates, "Mass balance of silica in straw from the perspective of silica reduction in straw pulp," Bioresources, vol. 7, no. 3, pp. 3274-3282, 2012.

[38] S. Neu, J. Schaller, and E. G. Dudel, "Silicon availability modifies nutrient use efficiency and content, C:N:P stoichiometry, and productivity of winter wheat (Triticum aestivum L.)," Scientific Reports, vol. 7, article 40829, 2017.

[39] H. A. Alyosef, D. Schneider, S. Wassersleben et al., "Meso/macroporous silica from miscanthus, cereal remnant pellets, and wheat straw," ACS Sustainable Chemistry \& Engineering, vol. 3, no. 9, pp. 2012-2021, 2015.

[40] M. Gocke, W. Liang, M. Sommer, and Y. Kuzyakov, "Silicon uptake by wheat: Effects of Si pools and pH," Journal of Plant Nutrition and Soil Science, vol. 176, no. 4, pp. 551-560, 2013.

[41] V. Pérez Cuadra and P. Hermann, "Characterization and macropattern of calcium oxalate phytoliths in Argentinean endemic species of Chenopodioideae (Amaranthaceae)," Quaternary International, vol. 287, pp. 83-88, 2013. 
[42] M. Pierantoni, R. Tenne, V. Brumfeld et al., "Plants and light manipulation: the integrated mineral system in okra leaves," Advanced Science, vol. 4, no. 5, article 16000416, 2017.

[43] B. S. Tubana, T. Babu, and L. E. Datnoff, "A review of silicon in soils and plants and its role in us agriculture: History and future perspectives," Soil Science, vol. 181, no. 9-10, pp. 393-411, 2016.

[44] D. Buraczyńska and F. Ceglarek, "Previous crop value of postharvest residues and straw of spring wheat, field pea and their mixtures for winter triticale part I. Weight and chemical composition of post-harvest residues and straw," Acta Scientiarum Polonorum, Agricultura, vol. 10, no. 2, pp. 3-18, 2011.

[45] I. R. Shaikh, R. A. Shaikh, A. A. Shaikh et al., "H-ZSM-5 zeolite synthesis by sourcing silica from the wheat husk Ash: characterization and application as a versatile heterogeneous catalyst in organic transformations including some multicomponent reactions," Journal of Catalysts, vol. 2015, Article ID 805714, 14 pages, 2015.

[46] B. Wang, Y. Huang, and J. Zhang, "Sulfur distribution during hydrothermal liquefaction of lignite, wheat straw and plastic waste in sub-critical water," China Petroleum Processing and Petrochemical Technology, vol. 17, no. 1, pp. 24-30, 2015.

[47] P. E. A. Debiagi, C. Pecchi, G. Gentile et al., "Extractives extend the applicability of multistep kinetic scheme of biomass pyrolysis," Energy \& Fuels, vol. 29, no. 10, pp. 6544-6555, 2015.

[48] L. Deng and D. Che, "Chemical, electrochemical and spectral characterization of water leachates from biomass," Industrial \& Engineering Chemistry Research, vol. 51, no. 48, pp. 15710-15719, 2012.

[49] L. Wang, G. Skjevrak, J. E. Hustad, and Ø. Skreiberg, "Investigation of biomass ash sintering characteristics and the effect of additives," Energy \& Fuels, vol. 28, no. 1, pp. 208-218, 2014.

[50] M. Nieves-Cordones, F. R. Al Shiblawi, and H. Sentenac, "Roles and transport of sodium and potassium in plants," Metal Ions in Life Sciences, vol. 16, pp. 291-324, 2016.

[51] M. Yamada, C. Kuroda, and H. Fujiyama, "Function of sodium and potassium in growth of sodium-loving Amaranthaceae species," Soil Science \& Plant Nutrition, vol. 62, no. 1, pp. 20-26, 2016.

[52] W. Guo, H. Nazim, Z. Liang, and D. Yang, "Magnesium deficiency in plants: An urgent problem," The Crop Journal, vol. 4, no. 2, pp. 83-91, 2016. 

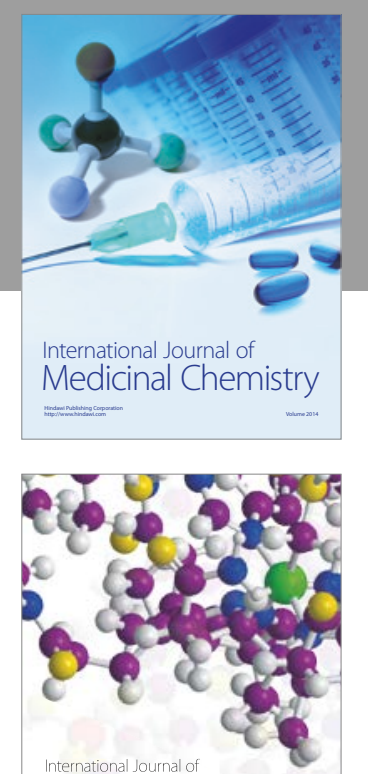

Carbohydrate Chemistry

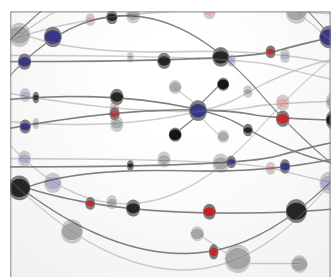

The Scientific World Journal
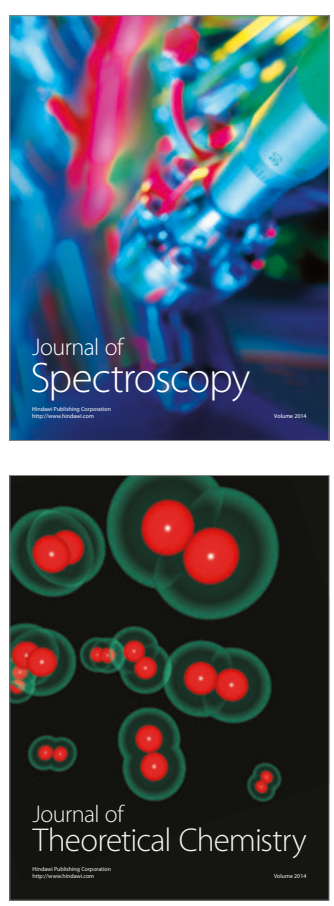
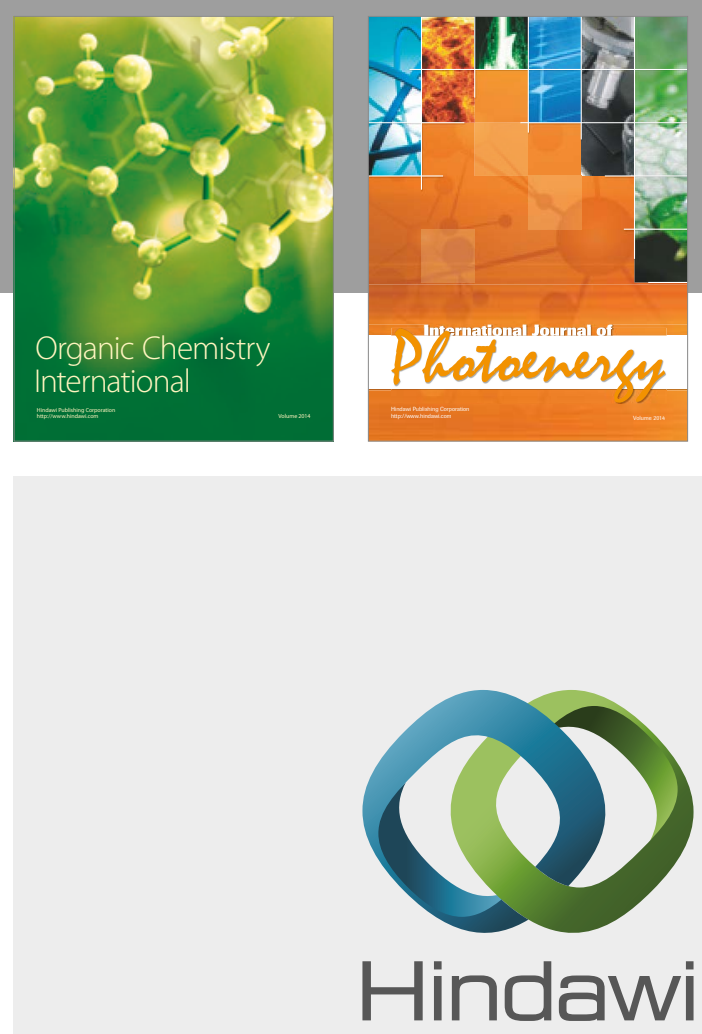

Submit your manuscripts at

https://www.hindawi.com

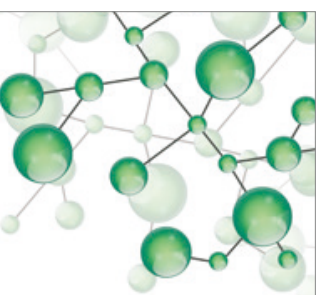

International Journal of

Inorganic Chemistry

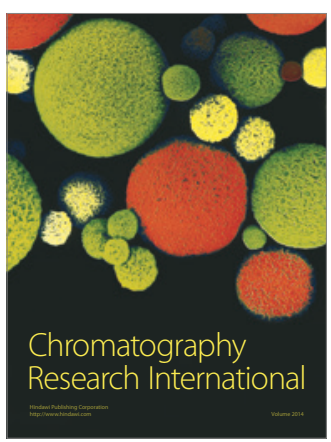

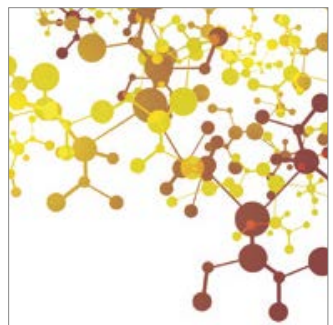

Applied Chemistry
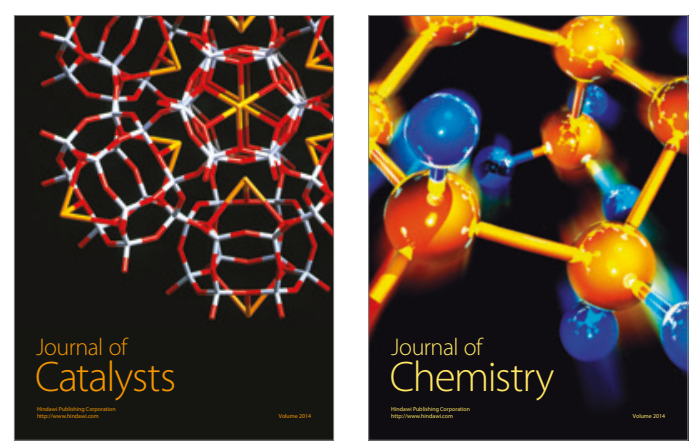
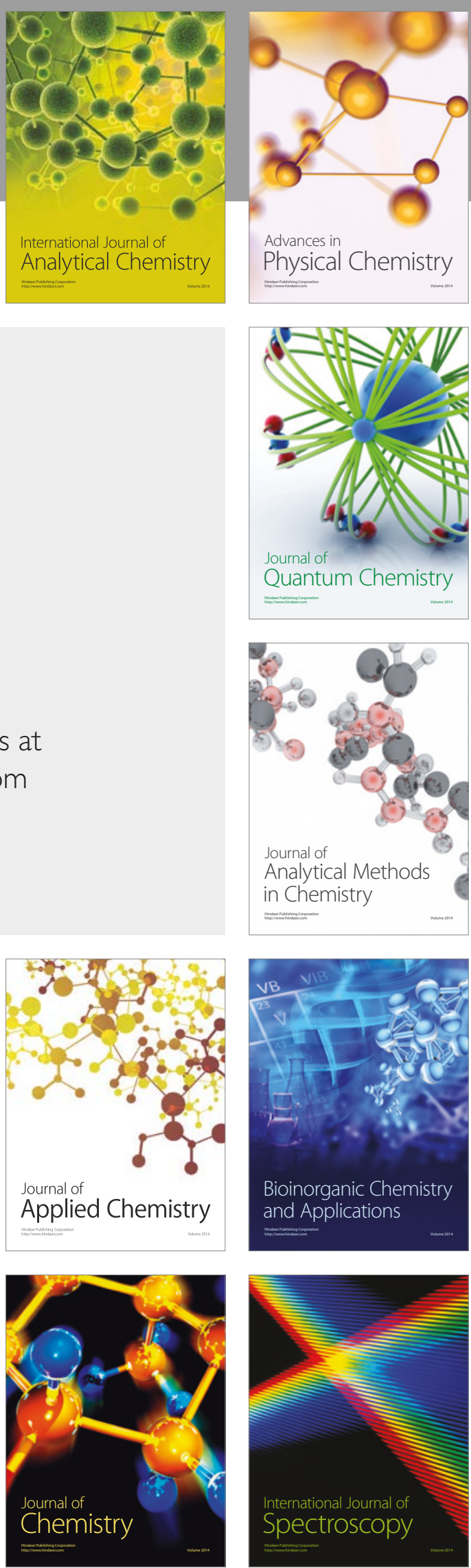